\title{
Minimizing Load Shedding in Electricity Networks using the Primary, Secondary Control and the Phase Electrical Distance between Generator and Loads
}

\author{
Nghia. T. Le ${ }^{1}$, Anh. Huy. Quyen ${ }^{2}$, Binh. T. T. Phan ${ }^{3}$, An. T. Nguyen ${ }^{4}$, Hau. H. Pham ${ }^{5}$ \\ Department of Electrical and Electronics Engineering \\ University of Technology and Education, (HCMUTE), Ho Chi Minh, 71313, Vietnam ${ }^{1,2,45}$ \\ HCMC University of Technology, (HCMUT), Ho Chi Minh City, 72506, Vietnam ${ }^{3}$
}

\begin{abstract}
This paper proposes a method for determining location and calculating the minimum amount of power load needed to shed in order to recover the frequency back to the allowable range. Based on the consideration of the primary control of the turbine governor and the reserve power of the generators for secondary control, the minimum amount of load shedding was calculated in order to recover the frequency of the power system. Computation and analysis of the phase electrical distance between the outage generator and the loads to prioritize distribution of the amount power load shedding at load bus positions. The nearer the load bus from the outage generator is, the higher the amount of load shedding will shed and vice versa. With this technique, a large amount of load shedding could be avoided, hence, saved from economic losses, and customer service interruption. The case study simulation has been verified through using PowerWorld sofware systems. The effectiveness of the proposed method tested on the IEEE 37 bus 9 generators power system standard has demonstrated the effectiveness of this method.
\end{abstract}

Keywords-Load shedding; primary control; secondary control; phase electrical distance

\section{INTRODUCTION}

The imbalance active power between the generation and the load demand causes a decrease the frequency in the power system. The monitoring and control system will immediately implement the control solution to restore the frequency back to the allowable value. In [1], the primary and secondary control power plants are set by automatic controlled equipment or the power system operator. At this point, the spinning reversed powers are considered to restore the frequency. After implementing all possible control solutions that the system's frequency has not yet recovered to the allowable value, the load shedding is considered as the final solution to restore the frequency and maintain the active power balance between the generation and load demand.

In reality, load shedding is often used as a low cost and effective method to prevent the system blackout [2] and instability. A good load shedding option is to shed minimum load amount as soon as possible while simultaneously satisfying all constraints to maintain system stability. The traditional solutions for this problem are found in [3] and [4], and both papers use under frequency load shedding relay (UFLS) or under voltage load shedding relay (UVLS). These conventional techniques are fixed amount of load shedding when the frequency or voltage deviates from the nominal value. According to [5], load cutting is usually performed on a step-by-step based on the expected load cutting schedules which determined on the general rules and operator experience. These tables indicate the amount of active power that should be shed at each step depending on the frequency variation. This could cause the over load shedding or the insufficient load shedding. The authors in [6], [7] and [8] present a method to estimate the amount load shedding, it is usually based on the frequency reduction, the rate of change of frequency (ROCOF) or swing equation. Intelligent load shedding methods have also been studied and developed such as artificial neural network (ANN) [9-10], fuzzy logic [11], genetic algorithm (GA) [12-13] and particle swarm optimization (PSO) algorithm [14-15]. These algorithms focus on determining when and how much load should be disconnected. The limitations of these methods have not determined the order of the load need to shed and have not properly distributed the amount of load shedding at the load buses. References [16] introduced a hybrid algorithm based on Genetic Algorithm (GA) and Neural Network (NN) for reducing the amount of load shedding and voltage collapse in power system. In [17] a load shedding technique based on sensitivity analysis and electrical voltage distance is used in order to get the distributed load shedding.

There are three requirements for a load shedding plan. First of all, the load shedding should be fast. Second, the frequency must be restored to allowable values. Finally, the amount of load shedding must be as low as possible.

In this paper, a new load shedding method based on frequency taking into account the effects of the primary control and the secondary control of the generators is presented. For this method, when the generator outage occurs, the turbine regulator of the generators will generate additional power into the grid. In case the system frequency does not recover to the allowable value, the frequency modulation power plants, as well as the other generators, will implement the secondary control strategy. After performing the secondary control that the frequency is still less than the permissible value, the load shedding must be done at the load buses. This amount of load shedding is determined by the quick, simple calculation formulas and it is lower than other traditional methods. 
On the other hand, the Phase Electrical Distance (PED) analysis between the generator node and the load nodes is used to prioritize the distribution of the amount of load shedding at each bus in the power system. The closer the load bus is to the outage generator position; the smaller the phase electrical distance is. Therefore, the greater the amount of load shedding power required to disconnect at these nodes.

The effectiveness of the proposed load shedding strategy was demonstrated through the test on the 9-machine, 37-bus system, and the results are compared with a conventional under-frequency load-shedding scheme. Calculated and simulated results showed that the proposed method was less the amount power of load shedding than the UFLS relay method, thus reducing the losses and inconvenience caused to customers using electricity. Besides, the recovery time and rotor deviation angle still guaranteed within the allowable values and maintained the stability of the power system. Therefore, in emergency situations such as: large generator outage, ... this proposed method can be used to support and train the dispatchers and operators of power systems in assisting with decisions on load shedding at power companies.

\section{Methodology}

\section{A. Overview the Power Systerm Frequency Respond}

First, the basic concepts of speed governing are best illustrated by considering an isolated generating unit supplying a local load as shown in Fig. 1.

The power system loads are a composite of a variety of electrical devices. For resistive loads, such as lighting and heating loads, the electrical power is independent of frequency. In the case of motor loads, such as fans and pumps, the electrical power changes with frequency due to changes in motor speed. According to [18], the overall frequencydependent characteristic of a composite load may be expressed as:

$$
\Delta P_{e}=\underset{\text { Nonfrequency-sensitive-load-change }}{\Delta P_{L}}+\underset{\text { Frequency-sensitive-load-change }}{D \Delta \omega}
$$

Where: $\Delta P_{L}$ Load component does not depend on frequency, eg heat load, lighting, ...; $D \Delta \varpi_{r}$ : The change in load depends on the change of frequency, eg, motors, pumps, etc; $\Delta \mathrm{P}_{\mathrm{e}}$ : Deviation of power change; $\Delta \omega_{\mathrm{r}}$ : Deviation of angle speed change; D: The percentage change in load with percentage of change in frequency varies, $\mathrm{D}$ is from $1 \div 2 \%$.

The governor with speed-droop characteristic can be used when two generators or more and adjust the speed (frequency) with deviation.

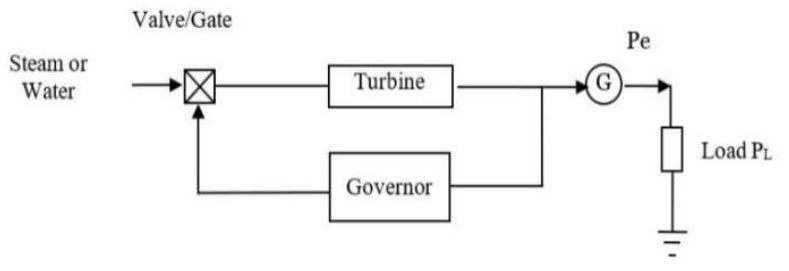

Fig. 1. Generator Provides Independent Load.
The author in [18] present the transfer function block diagram reflects the relationship between the load change and the frequency taking into account the governor characteristic, the prime mover and the load response is shown in Fig. 2.

The transfer function relating the load change, $\Delta P_{L}$, to the frequency change, $\Delta \omega$, is

$$
\Delta f(s)=\Delta P_{L}(s)\left[\frac{\frac{-1}{M s+D}}{1+\frac{1}{R}\left(\frac{1}{1+s T_{G}}\right)\left(\frac{1}{1+s T_{C H}}\right)\left(\frac{1}{M s+D}\right)}\right]
$$

Where: $\mathrm{K}_{\mathrm{G}}$ the amplification stage; $\omega_{\text {ref }}$ reference speed; $\mathrm{T}_{\mathrm{CH}}$ "charging time" time constant; $\Delta P_{\text {Valve }}$ per unit change in valve position from nominal; Ms angular momentum of the machine in Laplace transform; $\mathrm{R}$ is equal to pu change in frequency divided by pu change in unit output; it is characteristic for the sliding speed adjustment; $R=\frac{-\Delta f}{\Delta P}$

The purpose of system simulation in the form of a transfer function is to calculate the time response of the frequency deviation when the load change step is $\Delta \mathrm{P}_{\mathrm{L}}$. From the above description, frequency deviation in steady state it means the value of the transfer function is determined for $\mathrm{s}=0$ :

The steady-state value of $\Delta f(s)$ may be found by:

$$
\text { steady state }=\lim _{\substack{s \rightarrow f \\ s \rightarrow 0}}=\frac{-\Delta P_{L}\left(\frac{1}{D}\right)}{1+\left(\frac{1}{R}\right)\left(\frac{1}{D}\right)}=\frac{-\Delta P_{L}}{\frac{1}{R}+D}
$$

When the power system has multiple generators with independent governors, the frequency deviation in steady state when the load change is calculated according to formula (4).

$$
\Delta f=\frac{-\Delta P_{L}}{\frac{1}{R_{1}}+\frac{1}{R_{2}} \ldots+\frac{1}{R_{n}}+D}
$$

or:

$\Delta f=\frac{-\Delta P_{L}}{\frac{1}{R_{e q}}+D}$

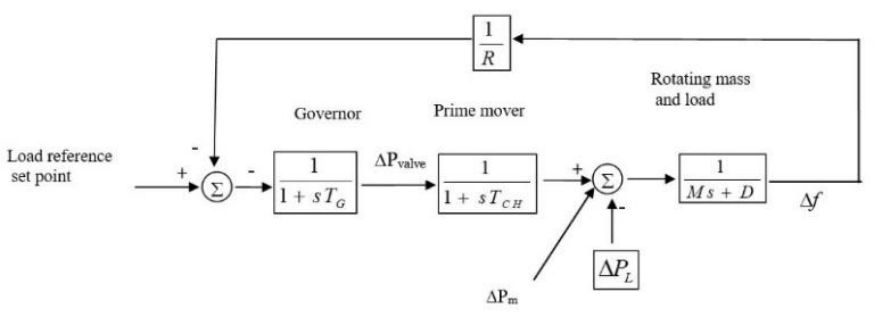

Fig. 2. The Transfer Function Block Diagram Describes the Relationship between the Load Changes and Frequency. 
Where, $R_{\mathrm{eq}}$ is the modulation coefficient of the equivalent governor of the whole power system.

$$
\begin{aligned}
& R_{e q}=\frac{1}{\frac{1}{R_{1}}+\frac{1}{R_{2}}+\ldots .+\frac{1}{R_{n}}} \\
& \quad \text { Set } \beta=\left(\frac{1}{R_{e q}}+D\right)^{-1} \text { is the general frequency response }
\end{aligned}
$$

characteristic of power system. It includes the adjustment characteristics of turbine mechanical power and load. From formula (4), obtain:

$$
\Delta f=-\Delta P_{L} \cdot \beta
$$

In [19], the effects of the governor speed droop and the frequency of load on the net frequency change are shown in Fig. 3.

\section{B. Primary and Secondary Frequency Control in the Power System}

Primary frequency control is an instantaneous adjustment process performed by a large number of generators with a turbine power control unit according to the frequency variation.

Secondary frequency control is the subsequent adjustment of primary frequency control achieved through the AGC's effect (Automatic Generation Control) on a number of units specifically designed to restore the frequency back to its nominal value or otherwise, the frequency-adjusting effects are independent of the governor's response called the secondary frequency control. The process of the primary and secondary frequency control was shown in Fig. 4.

Characteristic line (A) shows the effect of the governors: change the turbine power according to the change of frequency:

In balance mode, the intersection of the generator characteristic line (A) with the frequency characteristic of the load line (D) determines the frequency $\mathrm{f}_{0}$ equal $50 \mathrm{~Hz}$ (or 60 $\mathrm{Hz}$ ). When the load increases $\triangle \mathrm{PL}$, the new characteristic line will be line (E): $P_{t}+\Delta P$

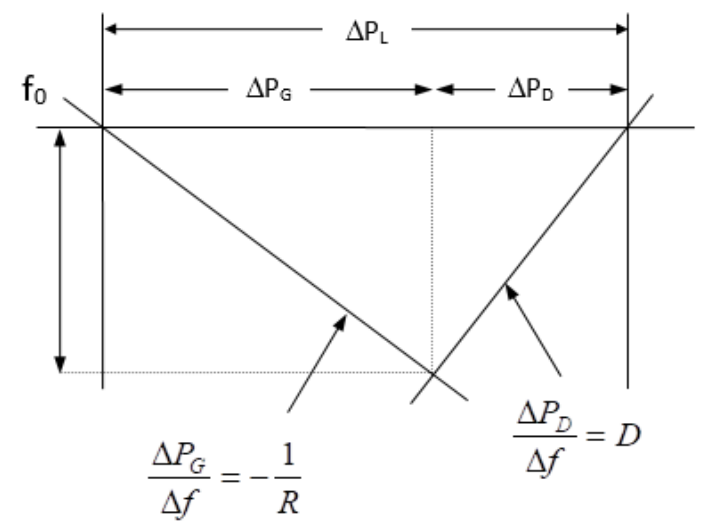

Fig. 3. Synthesized Frequency Response of the Power System.

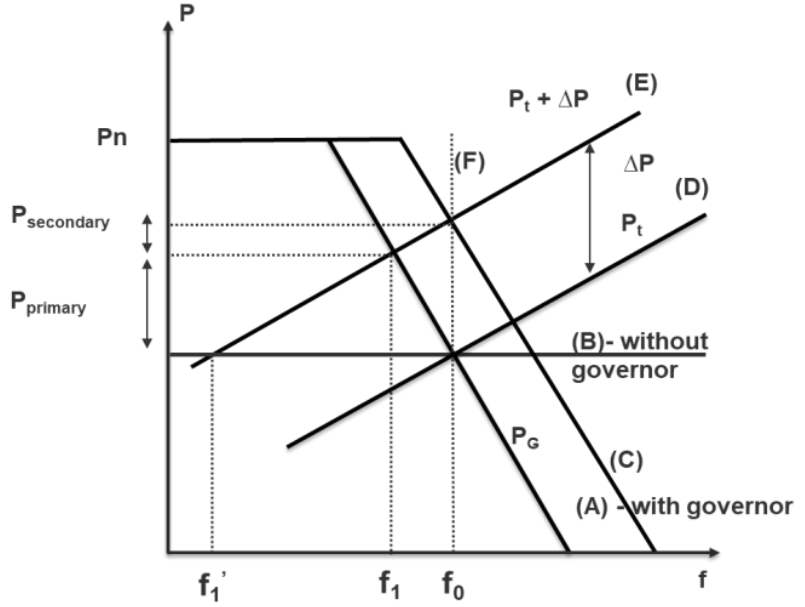

Fig. 4. The Relationship between Frequency Deviation and Output Power Deviation.

And, the intersection of the generator characteristic line (A) with the new load characteristic line (E) defines the new frequency $f_{1}$. Here, $f_{1}<f_{0}$. Compared to the case where the generator does not have a governor, characteristic line (B), it is clear that: $f_{1}<f_{0}$. According to the characteristic line (A) of the generator unit, the governor does not prevent the frequency reduction: $\Delta \mathrm{f}=\mathrm{f}_{0}-\mathrm{f}_{1}$

However, because the generator has the governor, it has helped to limit the large deviation of the frequency. Compared with the case the generators do not have a governor (B), the intersection with the new characteristic line of the load $(E)$ will determine the frequency $\mathrm{f}_{1}: \mathrm{f}_{1}<\mathrm{f}_{1}<\mathrm{f}_{0}$

Thus, the governor of the generator unit has the effect of reducing the large change of frequency known as the primary frequency controller. The efficiency of the primary frequency control depends on the slope of the speed-droop characteristic of the generator units. In the ideal case, the adjusting characteristic line $(F)$ of the generator unit is vertical line, the frequency will not change until the power limit of the generator unit Pn.

The above characteristics of the primary adjustment process lead to the need for external intervention (by the automatic control device or by the power system operators) that is the secondary frequency control process. The secondary adjustment characteristic is represented by the simultaneous shifting of the characteristic line (A) into the characteristic line $(\mathrm{C})$ of the generator unit, with the slope unchanged.

This adjustment is equivalent to the creation of a static vertical adjustment characteristic line $(\mathrm{F})$. Thus, the secondary adjustment is within the rated power range of the generator unit to restore and maintain the frequency within the allowable value.

\section{Calculate the Minimum Load Shedding Power Considering the Control Characteristic of Turbine Mechanical Power and Load}

Define In the $60 \mathrm{~Hz}$ power system, the frequency deviation allowed $\Delta f_{p}$ is $0.3 \mathrm{~Hz}\left(\Delta \mathrm{f}_{\mathrm{p}} \leq-0.3 \mathrm{~Hz}\right)$. Therefore, when computed in relative unit $(\mathrm{pu})$ : 


$$
\Delta f_{p} \leq \frac{-0.3}{60}(p u)
$$

Thus, from formula (5) the relationship between the permissible change in frequency, the amount of secondary control power and the minimum load shedding power $\mathrm{P}_{\mathrm{LSmin}}$ is calculated according to the proposed formula below:

$$
\Delta f_{p}=-\beta \cdot\left[\Delta P_{L}-\left(\Delta P_{\text {Secondary control }}+P_{L S \min }\right)\right]
$$

In this case, if $\left(\Delta \mathrm{P}_{\text {Secondary control }}+\Delta \mathrm{P}_{\mathrm{LS} \text { min }}\right)<\Delta \mathrm{P}_{\text {Sacondary max }}$, then $\Delta \mathrm{P}_{\mathrm{LSmin}}=0$, otherwise the minimum power load shedding is calculated by the formula below:

$$
P_{L S \min }=\Delta P_{L}-\left(\frac{-\Delta f_{p}}{\beta}\right)-\Delta P_{\text {Secondary Max }}
$$

Where: $\Delta f_{p}$ is the permissible change in frequency $(\mathrm{pu})$; $\mathrm{P}_{\mathrm{LS} \text { min }}$ is the minimum amount of power required to shed (pu); $\Delta \mathrm{P}_{\text {Secondary control }}$ is the amount of secondary control power addition to the system.

\section{Load Shedding Distribution}

The goal of the distribution the amount of load shedding power at load buses is to focus priority on load shedding at around or near the outage generators location. To do this, the concept of the phase electrical distance between two buses is used. The phase electrical distance between the outage generator and load buses is calculated using the proposed process in [20], which is performed as follows:

$$
D_{P}(i, j)=D_{P}(j, i)=X_{i i}+X_{j j}-2 \cdot X_{i j}
$$

Obviously, two buses electrically very close will always have a very small phase electrical distance. The smaller the phase electrical distance, the nearer the distance between the loads and the generator, and therefore, the smaller the total impedance $\mathrm{Z}$. When generator losses at bus $\mathrm{n}$, the amount of load shedding at different load buses can be calculated in the same way as the principle of the load sharing in the parallel circuit. The general formula calculates the load shedding distribution at nodes according to the phase electrical distance:

$$
P_{L S i}=\frac{D_{P, e q}}{D_{P, m i}} \cdot P_{L S \min }
$$

With

$$
D_{P, e q}=\frac{1}{\sum_{i \neq m} \frac{1}{D_{P, m i}}}
$$

Where: $\mathrm{m}$ is the number of generator bus; $\mathrm{i}$ : is the number of load bus; $\mathrm{P}_{\mathrm{LSi}}$ : the amount of load shedding power for the $\mathrm{i}$ bus (MW); $\mathrm{P}_{\mathrm{LS} \text { min }}$ : the minimum amount of load shedding power to the restore of frequency back to the allowable value (MW); $\mathrm{D}_{\mathrm{P}, \mathrm{mi}}$ : the phase electrical distance of the load to the $\mathrm{m}$ outage generator; $D_{\mathrm{P}, \text { eq }}$ : the equivalent phase electrical distance of all load buses and generator.

\section{Case Studies-Simulation and Results}

The effectiveness of the proposed method is tested on the IEEE 37 bus 9 generators system [21] single-line diagram which is shown in Fig. 5. The test system consists of 9 generators and 26 loads buses. The generator at Bus-31 are considered as the swing bus. Total the active power and the reactive power of the system are 1046.52 MW and 226.47 MVAR respectively under normal operating conditions. The maximum active power and reactive power of the system are $1087 \mathrm{MW}$ and 449 MVAR. $\mathrm{S}_{\text {base }}=100 \mathrm{MVA}$ for this test system. Parameters of the generators are shown in Table 1. The control solutions minimize the amount of load shedding and maintain steady-state frequency from 59.7 to $60 \mathrm{~Hz}$.

To test the effectiveness of the proposed method, the outage situations of the generator units are calculated, simulated and tested the parameters. In the case of calculations and simulations, the spinning reserved power to control the secondary frequency is also considered. All test cases are simulated on PowerWorld GSO 19 software. The results are compared with the results of the traditional load shedding method using under frequency load shedding relay, and presented in Table 6 .

Apply the (7), (9), (10) formulas calculate the system frequency, the amount of primary and secondary control power and the amount of load to be shed. The results of the computation of the outage generator situations are shown in Table 2.

In the test example, the sudden disconnection of the PEAR138 generator (bus 53) is simulated. Applying the equation (7) calculates the stable frequency value when the PEAR138 generator (bus 53) disconnects from the system. The frequency value is $59.6 \mathrm{~Hz}$, and shows in Fig. 6.

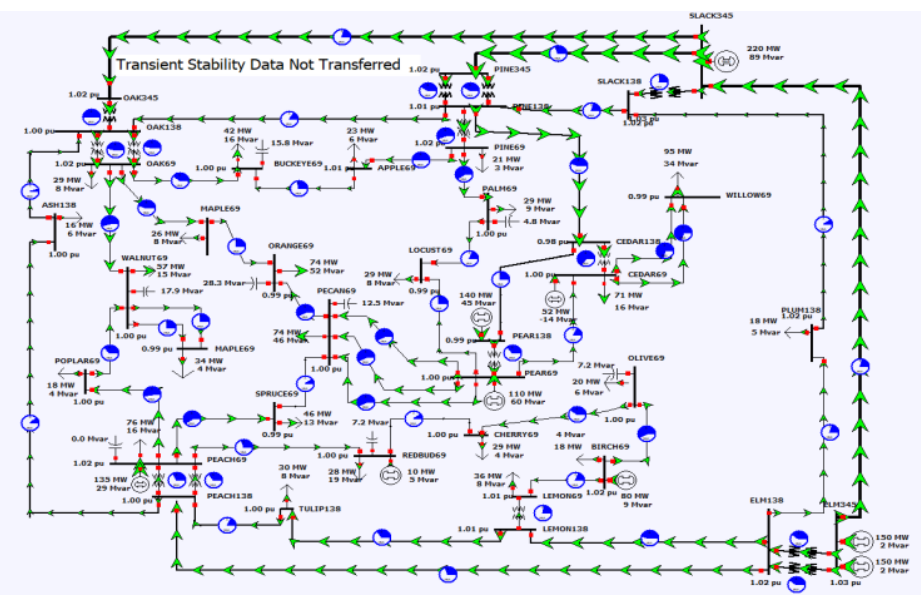

Fig. 5. The IEEE 37 Bus 9 Generators Test System. 
TABLE I. PARAMETERS OF THE GENERATORS IN THE IEEE 37 BUS 9 GENERATORS STANDARD POWER SYSTEM

\begin{tabular}{|c|c|c|c|c|c|c|c|}
\hline No. Gen & Name of Gen. Bus & S.new MVA & S.old MVA & R.old p.u & R.new p.u & $\beta(D=2 \%) p u$ & Max MW \\
\hline 1 & REDBUD69 & 100 & 40 & 0.05 & 0.125 & 0.00425 & 35 \\
\hline 2 & ELM345_1 & 100 & 180 & 0.05 & 0.028 & 0.00482 & 150 \\
\hline 3 & ELM345_2 & 100 & 180 & 0.05 & 0.028 & 0.00482 & 150 \\
\hline 4 & SLACK345 & 100 & 250 & 0.05 & 0.02 & 0.00517 & 220 \\
\hline 5 & PEACH69 & 100 & 160 & 0.05 & 0.031 & 0.00473 & 150 \\
\hline 6 & CEDAR69 & 100 & 57 & 0.05 & 0.088 & 0.00431 & 52 \\
\hline 7 & BIRCH69 & 100 & 85 & 0.05 & 0.059 & 0.00442 & 80 \\
\hline 8 & PEAR138 & 100 & 150 & 0.05 & 0.033 & 0.00469 & 140 \\
\hline 9 & PEAR69 & 100 & 115 & 0.05 & 0.043 & 0.00454 & 110 \\
\hline
\end{tabular}

TABLE II. THE OUTAGE GENERATORS CASES

\begin{tabular}{|l|l|l|l|l|l|}
\hline Name of Gen. Bus & $\begin{array}{l}\text { Frequency } \\
\text { (Hz) }\end{array}$ & $\begin{array}{l}\text { In the allow } \\
\text { range }\end{array}$ & $\begin{array}{l}\text { The primary } \\
\text { control power value } \\
\text { (MW) }\end{array}$ & $\begin{array}{l}\text { The secondary control } \\
\text { power value (MW) }\end{array}$ & $\begin{array}{l}\text { The amount of } \\
\text { shedding power } \\
\text { (MW) }\end{array}$ \\
\hline REDBUD & 59.97 & Yes & 10 & 0 & 0 \\
\hline ELM345\#1 & 59.56 & No & 150 & 7.72 & 38.57 \\
\hline ELM345\#2 & 59.56 & No & 150 & 7.72 & 38.57 \\
\hline PEACH69 & 59.62 & No & 134.6 & 0 & 13.22 \\
\hline CEDAR69 & 59.86 & Yes & 52 & 0 & 0 \\
\hline BIRCH69 & 59.79 & No & 80 & 18.2 & 0 \\
\hline PEAR138 & 59.6 & Yes & 110 & 0 \\
\hline PEAR69 & 59.7 & & \\
\hline
\end{tabular}

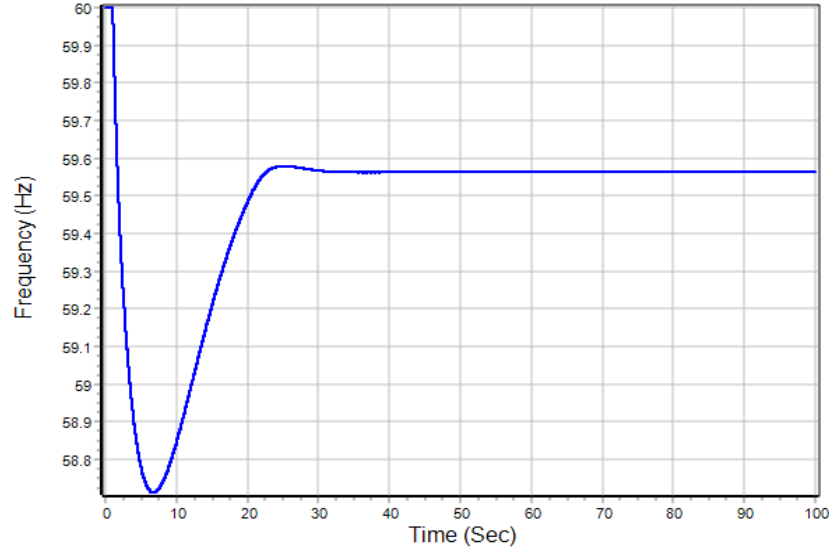

Fig. 6. The Frequency of the System when the PEAR138 Generator Disconnects.

After the PEAR138 generator suddenly disconnects, the frequency value is less than the allowable value. Therefore, the primary control and secondary frequency control which presented in section II.B for frequency recovery should be implemented. The primary control process is done automatically by the turbine governor after the PEAR138 outage generator. The value of the primary control power of each generator turbine is shown in Table 3.
Because the recovery frequency is less than the allowable value, so the secondary control is implemented after the primary control. The spinning reversed power of the generators will be mobilized to perform the secondary control. In this case, the secondary control power is $18.2 \mathrm{MW}$. The frequency of the system after the implementation of the secondary control is shown in Fig. 7.

TABLE III. THE VALUE OF THE PRIMARY CONTROL POWER OF THE GENERATORS

\begin{tabular}{|l|l|}
\hline Generator & $\begin{array}{l}\text { The increased primary control power of } \\
\text { each generator }(\mathbf{M W})\end{array}$ \\
\hline REDBUD69 (bus 14) & 5.2 \\
\hline ELM345\#1 (bus 28) & 23.6 \\
\hline ELM345\#2 (bus 28) & 23.6 \\
\hline SLACK345 (bus 31) & 32.8 \\
\hline PEACH69 (bus 44) & 21 \\
\hline CEDAR69 (bus 48) & 7.5 \\
\hline BIRCH69 (bus 50) & 11.2 \\
\hline PEAR138 (bus 53) & 0 \\
\hline PEAR69 (bus 54) & 15.1 \\
\hline & Total $=140 \mathrm{MW}$ \\
\hline
\end{tabular}




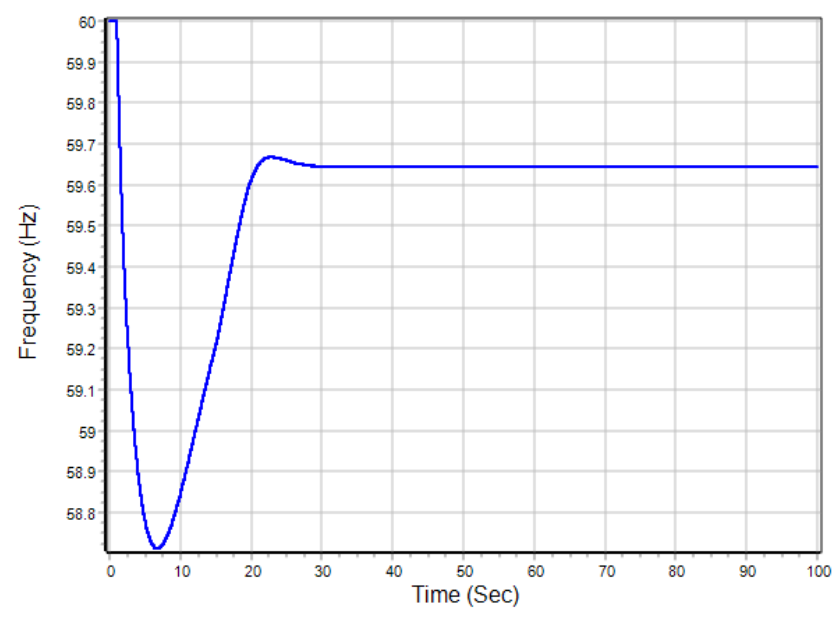

Fig. 7. The Frequency of the System after the Implementation of Primary and Secondary Control.

Thus, after performing the secondary control, the recovery frequency is $59.65 \mathrm{~Hz}$ and has not yet returned to the allowed value. Therefore, the final solution is load shedding. Equation
(10) is applied to calculate the minimum amount of load shedding power to recovery the frequency in allowable value.

$$
\begin{aligned}
& P_{L S \min }=\Delta P_{L}-\left(\frac{\Delta f_{p}}{\beta}\right)-\Delta P_{\text {Secondary Max }} \\
& =1.4-\left(\frac{0.3}{0.0047 x 60}\right)-0.182=0.1542 p u=15.42 M W
\end{aligned}
$$

After calculating the minimum discharge capacity, the distribution of the layoffs at the loaded buses is done. The layoff power distribution is based on the phase-to-phase reciprocal sensitivity value between the PEAR138 transmitter and the load buttons.

After calculating the minimum load shedding power, the load shedding distribution at the load buses is calculated. The amount of load shedding at load buses based on the phase electrical distance between the PEAR138 generator and the load buses. Calculation steps at Section II.D are applied to calculate the phase electrical distance between the PEAR138 generator and the load buses. The calculated results are shown in Table 4.

\begin{tabular}{|c|c|c|c|c|c|c|c|}
\hline $\begin{array}{l}\text { Order by the phase } \\
\text { electrical distance } \\
\text { increases }\end{array}$ & $\begin{array}{l}\text { Generator } \\
\text { REDBUD69 } \\
\text { (BUS 14) }\end{array}$ & $\begin{array}{l}\text { Generator } \\
\text { ELM345 (BUS } \\
\text { 28) }\end{array}$ & $\begin{array}{l}\text { Generator } \\
\text { PEACH69 } \\
\text { (BUS 44) }\end{array}$ & $\begin{array}{l}\text { Generator } \\
\text { CEDAR69 } \\
\text { (BUS 48) }\end{array}$ & $\begin{array}{l}\text { Generator } \\
\text { BIRCH69 } \\
\text { (BUS 50) }\end{array}$ & $\begin{array}{l}\text { Generator } \\
\text { PEAR138 } \\
\text { (BUS 53) }\end{array}$ & $\begin{array}{l}\text { Generator } \\
\text { PEAR69 } \\
\text { (BUS 54) }\end{array}$ \\
\hline 1 & Bus 14 & Bus 56 & Bus 44 & Bus 48 & Bus 50 & Bus 53 & Bus 54 \\
\hline 2 & Bus 34 & Bus 30 & Bus 30 & Bus 21 & Bus 20 & Bus 54 & Bus 15 \\
\hline 3 & Bus 44 & Bus 12 & Bus 3 & Bus 54 & Bus 33 & Bus 48 & Bus 53 \\
\hline 4 & Bus 20 & Bus 3 & Bus 12 & Bus 53 & Bus 34 & Bus 15 & Bus 48 \\
\hline 5 & Bus 30 & Bus 44 & Bus 24 & Bus 15 & Bus 30 & Bus 16 & Bus 16 \\
\hline 6 & Bus 3 & Bus 10 & Bus 15 & Bus 16 & Bus 14 & Bus 21 & Bus 27 \\
\hline 7 & Bus 12 & Bus 54 & Bus 54 & Bus 27 & Bus 44 & Bus 27 & Bus 24 \\
\hline 8 & Bus 50 & Bus 15 & Bus 5 & Bus 24 & Bus 3 & Bus 12 & Bus 12 \\
\hline 9 & Bus 33 & Bus 53 & Bus 16 & Bus 12 & Bus 12 & Bus 24 & Bus 21 \\
\hline 10 & Bus 15 & Bus 16 & Bus 53 & Bus 10 & Bus 56 & Bus 10 & Bus 10 \\
\hline 11 & Bus 54 & Bus 27 & Bus 27 & Bus 44 & Bus 15 & Bus 3 & Bus 44 \\
\hline 12 & Bus 24 & Bus 48 & Bus 10 & Bus 3 & Bus 54 & Bus 44 & Bus 3 \\
\hline 13 & Bus 5 & Bus 24 & Bus 56 & Bus 30 & Bus 24 & Bus 30 & Bus 30 \\
\hline 14 & Bus 16 & Bus 17 & Bus 48 & Bus 56 & Bus 53 & Bus 56 & Bus 55 \\
\hline 15 & Bus 53 & Bus 19 & Bus 14 & Bus 55 & Bus 10 & Bus 17 & Bus 56 \\
\hline 16 & Bus 27 & Bus 33 & Bus 18 & Bus 17 & Bus 16 & Bus 55 & Bus 17 \\
\hline 17 & Bus 56 & Bus 21 & Bus 37 & Bus 13 & Bus 27 & Bus 13 & Bus 13 \\
\hline 18 & Bus 10 & Bus 18 & Bus 33 & Bus 19 & Bus 48 & Bus 19 & Bus 19 \\
\hline 19 & Bus 48 & Bus 5 & Bus 17 & Bus 18 & Bus 5 & Bus 18 & Bus 18 \\
\hline 20 & Bus 18 & Bus 13 & Bus 21 & Bus 5 & Bus 18 & Bus 5 & Bus 5 \\
\hline 21 & Bus 37 & Bus 37 & Bus 19 & Bus 37 & Bus 17 & Bus 37 & Bus 37 \\
\hline 22 & Bus 17 & Bus 55 & Bus 34 & Bus 33 & Bus 37 & Bus 33 & Bus 33 \\
\hline 23 & Bus 21 & Bus 14 & Bus 13 & Bus 14 & Bus 21 & Bus 14 & Bus 14 \\
\hline 24 & Bus 19 & Bus 50 & Bus 55 & Bus 34 & Bus 19 & Bus 34 & Bus 34 \\
\hline 25 & Bus 13 & Bus 34 & Bus 50 & Bus 50 & Bus 13 & Bus 50 & Bus 50 \\
\hline 26 & Bus 55 & Bus 20 & Bus 20 & Bus 20 & Bus 55 & Bus 20 & Bus 20 \\
\hline
\end{tabular}

TABLE IV. The Phase Electrical Distance Between Generators and the LoAd Buses 


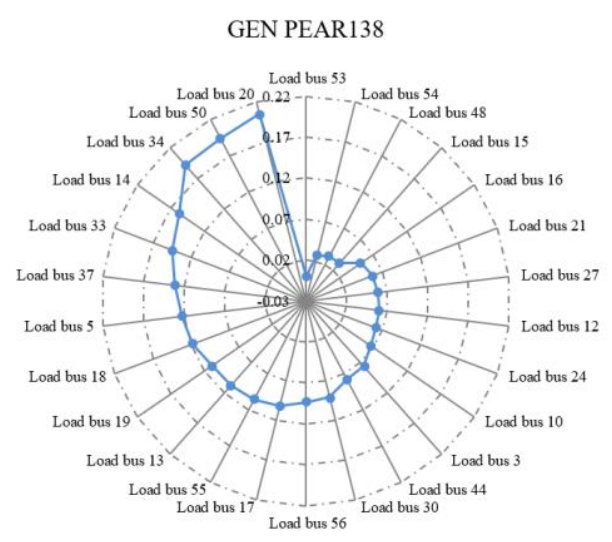

Fig. 8. The Phase Electrical Distance between the PEAR138 Generator and the Load Buses.

The phase electrical distance relationship between the PEAR138 generator and the load buses is shown in Fig. 8. Observe Fig. 8, which shows that the load buses nearer to the outage generator the lower PED; and the further to the outage generator, the greater the PED.

The priority load shedding distribution for each load bus is calculated based on the following principle: The nearer the load bus from the generator outage, the greater the amount of shedding power. Equation (12) in Section II.D is applied to calculate the amount of disconnection power value at the load buses. Calculated results are presented in Table 5.

TABLE V. THE LOAD SHEDDING DisTRIBUTION AT LOAD BUSES

\begin{tabular}{|l|l|}
\hline Load bus & $\begin{array}{l}\text { The shedding power at } \\
\text { the load buses (MW) }\end{array}$ \\
\hline Bus 3 & 0.578513 \\
\hline Bus 5 & 0.362864 \\
\hline Bus 10 & 0.67826 \\
\hline Bus 12 & 0.736799 \\
\hline Bus 13 & 0.412951 \\
\hline Bus 14 & 0.283504 \\
\hline Bus 15 & 1.372672 \\
\hline Bus 16 & 0.862628 \\
\hline Bus 17 & 0.437589 \\
\hline Bus 18 & 0.376409 \\
\hline Bus 19 & 0.408538 \\
\hline Bus 20 & 0.217464 \\
\hline Bus 21 & 0.776333 \\
\hline Bus 24 & 0.720498 \\
\hline Bus 27 & 0.764106 \\
\hline Bus 30 & 0.488855 \\
\hline Bus 33 & 0.308558 \\
\hline Bus 34 & 0.23262 \\
\hline Bus 37 & 0.34066 \\
\hline Bus 44 & 0.5695 \\
\hline Bus 48 & 1.418488 \\
\hline Bus 50 & 0.229534 \\
\hline Bus 54 & 1.615205 \\
\hline Bus 55 & 0.420893 \\
\hline Bus 56 & 0.476559 \\
\hline
\end{tabular}

In order to compare the effectiveness of the proposed method, the load shedding method using under frequency load shedding relay is used to compare. The process of UFLS is implemented when the frequency reduces below the frequency setting threshold. The load is usually cut step-by-step based on the load shedding table that pre-designed based on the general rule and operator experience. These tables guide the amount of load that should be cut at each step depending on the decrease of frequency. These values are shown in Table 6.

The frequency and the rotor angle comparison between the proposed method and the UFLS method are presented in Fig. 9 and Fig. 10.

It can be seen that the proposed load shedding method has less the amount of shedding $(77.85 \mathrm{MW})$ than the UFLS. Here, the recovery frequency value of the proposed method is lower than the UFLS method. However, this value is still within allowable parameter and acceptable range $(59.7 \mathrm{~Hz})$. Especially, when considering the phase angle recovery time of the proposed method is equivalent to the UFLS method, although this method has less the amount of load shedding than UFLS method. This can be explained by the fact that a large load at load nodes close to the generator are disconnected causing the phase angle to recover faster.

TABLE VI. The UFLS SCHEME USING LOAD SHEDDING TABLE [4]

\begin{tabular}{|l|l|l|l|l|}
\hline $\begin{array}{l}\text { The } \\
\text { steps } \\
\text { UFLS }\end{array}$ & $\begin{array}{l}\text { Frequency } \\
\text { (Hz) }\end{array}$ & $\begin{array}{l}\text { Time } \\
\text { delay } \\
(\mathbf{s})\end{array}$ & $\begin{array}{l}\text { The amount of } \\
\text { load shedding } \\
\text { the percent of } \\
\text { total load) }(\%)\end{array}$ & $\begin{array}{l}\text { Total amount } \\
\text { of load } \\
\text { shedding }(\%)\end{array}$ \\
\hline A & 59.7 & 0.28 & 9 & 9 \\
\hline B & 59.4 & 0.28 & 7 & 16 \\
\hline C & 59.1 & 0.28 & 7 & 23 \\
\hline D & 58.8 & 0.28 & 6 & 34 \\
\hline E & 58.5 & 0.28 & 5 & 46 \\
\hline F & 58.2 & 0.28 & 7 & 29 \\
\hline J & 59.4 & 10 & 5 & \\
\hline
\end{tabular}

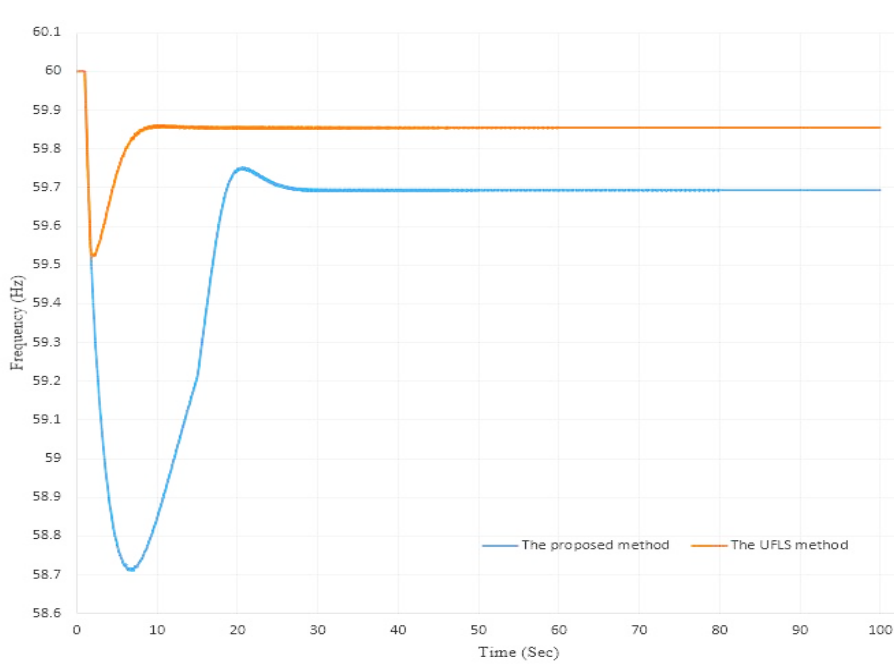

Fig. 9. The Frequency Comparison between the Proposed Method and the Traditional Method. 


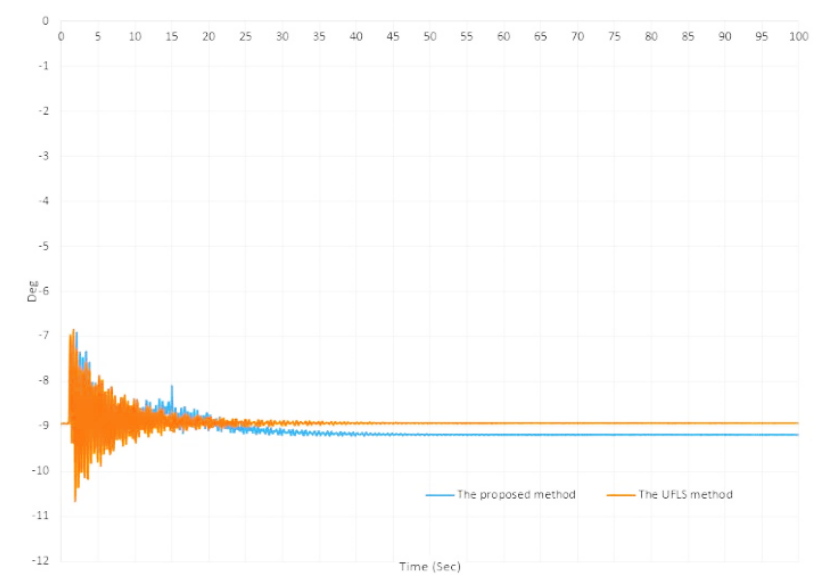

Fig. 10. The Rotor Angle Comparison between the Proposed Method and Traditional Method.

\section{CONCLUSIONS}

A load shedding method considers to the primary and secondary control elements of the power plant to calculate the minimum amount of load shedding power and restore the frequency back to the allowable value. The proposed method ensures the frequency and rotor angle stability of the system in case of a severe generation-load mismatch. The selection of location and distribution of load shedding power at load buses are based on the phase electrical distance concept.

The effectiveness of the proposed method has been demonstrated on a 9-machine, 37-bus system under different test cases. The performance of this is found to be better than that of a conventional UFLS scheme. The test results show that the proposed method results in reduced amount of load shedding while satisfying the operating conditions and limitations of the network. In the future work, the load shedding problem should consider the following factors: minimum the economic and technical losses, cost of customer service interruption, penalty costs, ... To solve this multiobjective problem, algorithms such as Genetic, PSO, and Fuzzy logic combined with ANN should be considered.

\section{ACKNOWLEDGMENT}

This research was supported by the HCMC University of Technology and Education, Grant no. T2019-41TĐ.

\section{REFERENCES}

[1] Sam Weckx, Reinhilde D'Hulst, Johan Driesen, "Primary and Secondary Frequency Support by a Multi-Agent Demand Control System", IEEE Transactions on Power Systems, Vol. 30, Issue: 3, pp. 1394 - 1404, 2015.

[2] Tang J, Liu J, Ponci F, Monti A, "Adaptive load shedding based on combined frequency and voltage stability assessment using synchrophasor measurements", IEEE Transactions on Power Systems, Vol.28, Issue: 2, pp. 2035-47, 2013.

[3] Delfino B, Massucco S, Morini A, Scalera P, Silvestro F. Implementation and comparison of different under frequency load- shedding schemes, Power Engineering Society Summer Meeting. Conference Proceedings, pp. 307-312, 2001.

[4] Amraee T, Mozafari B, Ranjbar AM, "An improved model for optimal under voltage load shedding: particle swarm approach", IEEE Power India Conference, pp. 6, 2006.

[5] B. Farahani, M. Abedi, "An Optimal Load-Shedding Scheme During Contingency Situations Using Meta-Heuristics Algorithms with Application of AHP Method", 11th International on Optimization of Electrical and Electronic Equipment, pp. 167-173, 2008.

[6] Lukas Sigrist, "A UFLS Scheme for Small Isolated Power Systems Using Rate-of-Change of Frequency", IEEE Transactions on Power Systems, Vo: 30, Issue: 4, pp. 2192 - 2193, 2015.

[7] Turaj Amraee, Mohammad Ghaderi Darebaghi, Alireza Soroudi, Andrew Keane, "Probabilistic Under Frequency Load Shedding Considering RoCoF Relays of Distributed Generators", IEEE Transactions on Power Systems, Vol: 33, pp. 3587 - 3598, 2018.

[8] V. V. Terzija, "Adaptive Under Frequency Load Shedding Based on the Magnitude of the Disturbance Estimation", IEEE Transactions on Power Systems, Vol. 21, No. 3, pp. 1260 - 1266, 2006.

[9] C. T. Hsu, M. S. Kang and C. S. Chen, "Design of Adaptive Load Shedding by Artificial Neural Networks", IEE Generation, Transmission, Distribution, Vol. 152, No. 3, pp. 415-421, 2005.

[10] S. Padrón, M. Hernández, A. Falcón, "Reducing Under-Frequency Load Shedding in Isolated Power Systems Using Neural Networks. Gran Canaria: A Case Study", IEEE Transactions on Power Systems, Vol. 31, Issue: 1, pp. $63-71,2016$.

[11] Houda Jouini, Kamel Jemai, and Souad Chebbi, "Voltage Stability Control of Electrical Network Using Intelligent Load Shedding Strategy Based on Fuzzy Logic," Mathematical Problems in Engineering, Vol. 2010, pp. 1-17, 2010.

[12] W. P. Luan, M. R. Irving, J. S. Daniel, "Genetic Algorithm for Supply Restoration and Optimal Load Shedding in Power System Distribution Networks", IEEE Generation, Transmission, Distribution, Vol. 149, No. 2, pp. 145-51, 2002.

[13] Ying-Yi Hong, Po-Hsuang Chen, "Genetic-Based Underfrequency Load Shedding in a Stand-Alone Power System Considering Fuzzy Loads", IEEE Transactions on Power Delivery, Vol. 27, Issue: 1, pp. 87-95, 2012.

[14] T. Amraee, B. Mozafari, A. M. Ranjbar, "An Improved Model for Optimal Under Voltage Load Shedding, Particle Swarm Approach", IEEE Power Conf. India, 2006.

[15] AbbasKetabi, MasoudHajiakbari Fini, "Adaptive underfrequency load shedding using particle swarm optimization algorithm", Journal of Applied Research and Technology, Vol. 15, Issue: 1, pp. 54-60, 2017.

[16] V.Tamilselvan, T.Jayabarathi, "A hybrid method for optimal load shedding and improving voltage stability", Ain Shams Engineering Journal, Vol. 7, Issue: 1, pp. 223-232, 2016.

[17] M Prasad, K N Satish, Kuldeep, Ranjana Sodhi, "A synchrophasor measurements based adaptive underfrequency load shedding scheme", IEEE Innovative Smart Grid Technologies - Asia (ISGT ASIA), 2014.

[18] Allen J. Wood, Bruce F. Wollenberg, Gerald B. Sheblé, "Power Generation, Operation and Control", Third Edition, John Wiley \& Sons, Inc., pp. $473-481,2014$.

[19] Prabha Kundur, "Power System Stability and Control", First Edition, McGraw-Hill Inc, pp. 597, 1994.

[20] L. Patrick, "The different electrical distance," in Proceedings of the Tenth Power Systems Computation Conference, Graz, pp. 542-550, 1990.

[21] J. Duncan Glover, Mulukutla S. Sarma, Thomas J. Overbye, "Power System Analysis and Design", Sixth Edition, Cengage Learning, pp. $718,2017$. 